Journal of Mechanical Engineering and Sciences (JMES)

ISSN (Print): 2289-4659; e-ISSN: 2231-8380; Volume 1, pp. 113-123, December 2011

(C) Universiti Malaysia Pahang, Pekan, Pahang, Malaysia

DOI: http://dx.doi.org/10.15282/jmes.1.2011.10.0010

\title{
REDUCTION OF OIL CONTAMINATION ON HARD DISK DRIVE PARTS USING AUTOMATIC HYDROCARBON WASHING MACHINE
}

\author{
Somkiat Tangjitsitcharoen and Nuntawat Nunya \\ Department of Industrial Engineering, Chulalongkorn University, \\ Patumwan, Bangkok 10330, Thailand; Phone +66 22186814 \\ E-mail: somkiat.t@eng.chula.ac.th
}

\begin{abstract}
This paper discusses the use of the Taguchi method and response surface analysis to minimize the proportion of defectives by oil contamination on one product of hard disk drive parts by using an automatic hydrocarbon washing machine. The experiments are conducted by using the Taguchi method and the matrices of washing conditions include nine parameters. The effect on the proportion of defectives by oil contamination is evaluated and determined. A second-order model is developed based on the parameters of the automatic hydrocarbon washing machine and the proportion of defectives of oil contamination determined by using the response surface method. The experimental results show that the parameters are significant. The developed model can be used effectively to predict the response.
\end{abstract}

Keywords: Hard disk drive part; proportion of defectives; oil contamination; Taguchi method; response surface analysis.

\section{INTRODUCTION}

Normally, an automatic hydrocarbon washing machine is used to clean hard disk drive parts in order to reduce the number of defectives caused by oil contamination. Hence, it is necessary to employ both optimization techniques to establish the optimal washing parameters and response models to reduce the defectives due to oil contamination. The Taguchi method and response surface analysis are used for those purposes in this research. The Taguchi method and the response surface methodology have been applied for optimizing geometric errors in surface grinding processes (Kwak, 2005), the minimizing of surface roughness in the turning of discontinuously reinforced aluminum composites (DRACs) under dry cutting conditions (Shetty et al., 2008), and biodiesel production from alkali catalyzed transesterification of waste cooking oil (Reddy, Kumar, Reddy, Vijaya, \& Kumari, 2009). Angsumalin, Somkiat, and Napassavong (2008) and Kadirgama, Rahman, Bakar, and Abou-El-Hossein (2009a) used statistical techniques for standardizing and optimizing the washing of machining parts and the surface roughness of milling mold 6061-T6 aluminum alloys with carbide coated inserts, respectively. Yang and Tarng (1998) utilized the Taguchi method to design optimization for quality as a powerful tool. Response surface analysis has been used to predict the effect of torque in end-milling (Kadirgama, Noor, Rahman, Rejab, Haron, \& Abou-ElHossein, 2009b). Sahin and Motorcu (2005) developed a surface roughness model by utilizing the response surface method (RSM), which was more practical, economical, and easier to use. In this research, the proportion of defectives of oil contamination washed by an automatic hydrocarbon washing machine is evaluated, and a second-order model is developed to predict the proportion of defectives of oil contamination. 


\section{METERIALS AND METHOD}

\section{Experimental setup and equipment}

The part called "Shaft Aries" is adopted for the experiments in the washing process, and its specification is shown in Figure 1. The experiments are carried out using the Careclean PC hydrocarbon. The automatic hydrocarbon washing machine and its flow process are shown in Figures 2 and 3.

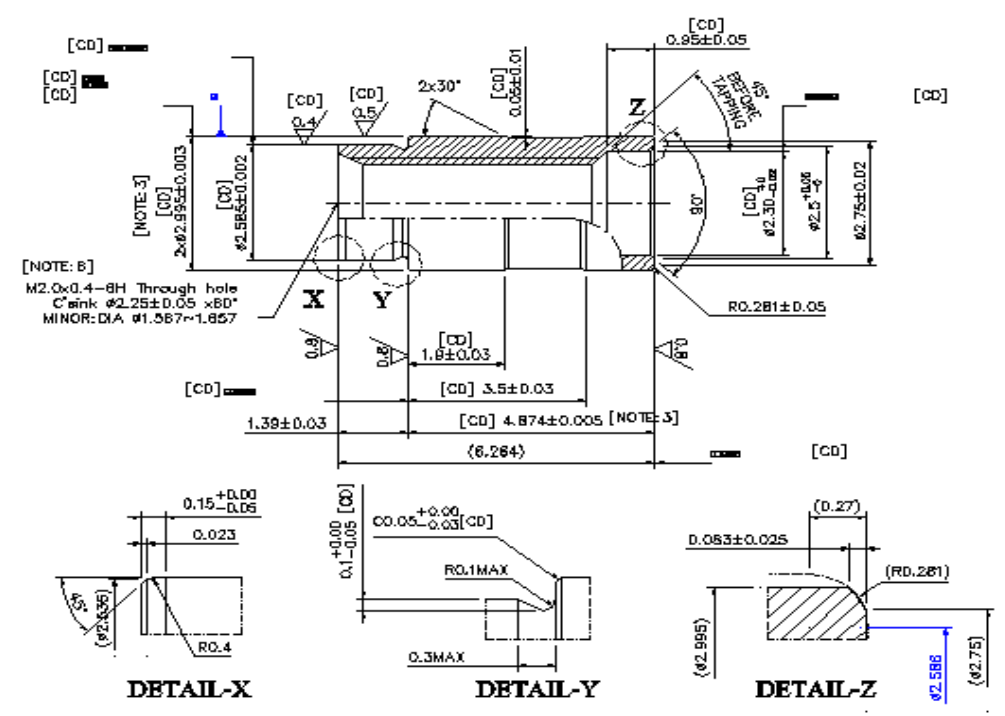

Figure 1. Illustration of the specification of the Shaft Aries part

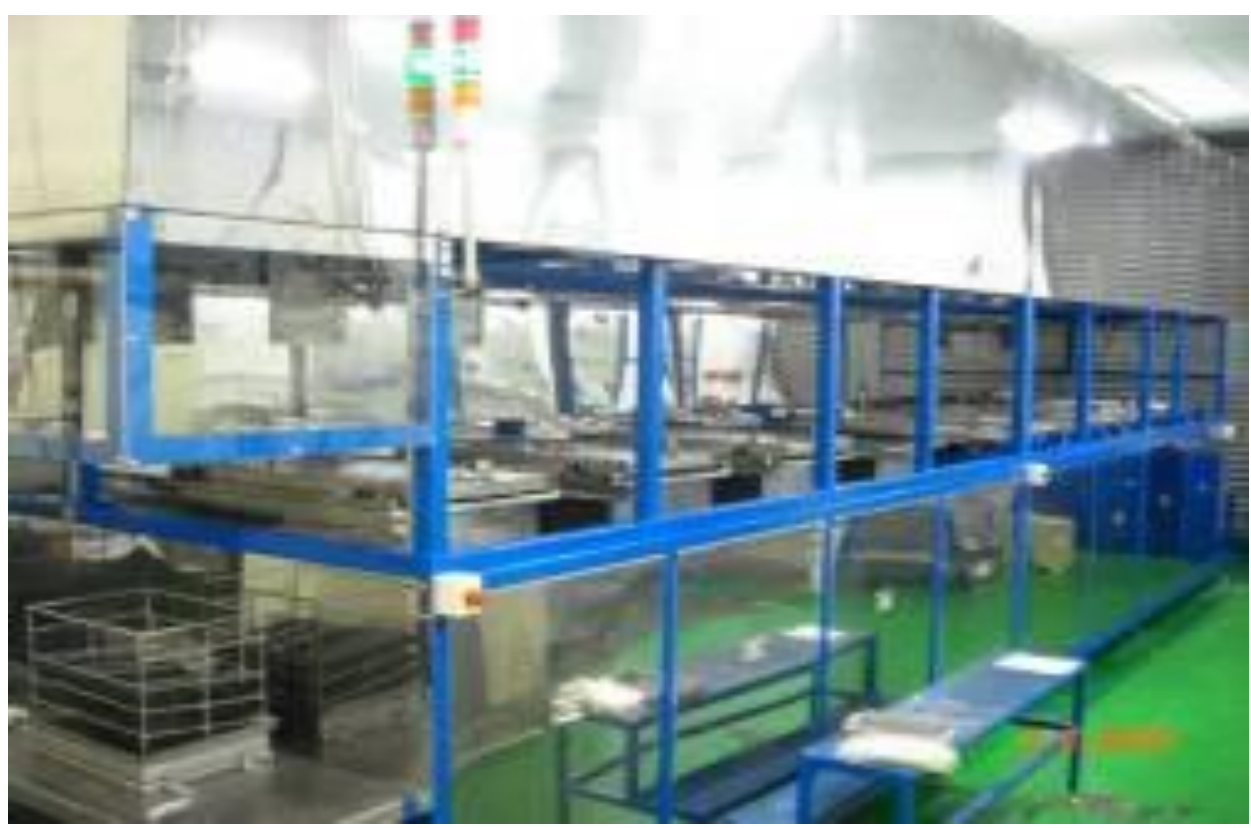

Figure 2. Automatic hydrocarbon washing machine and experimental setup 


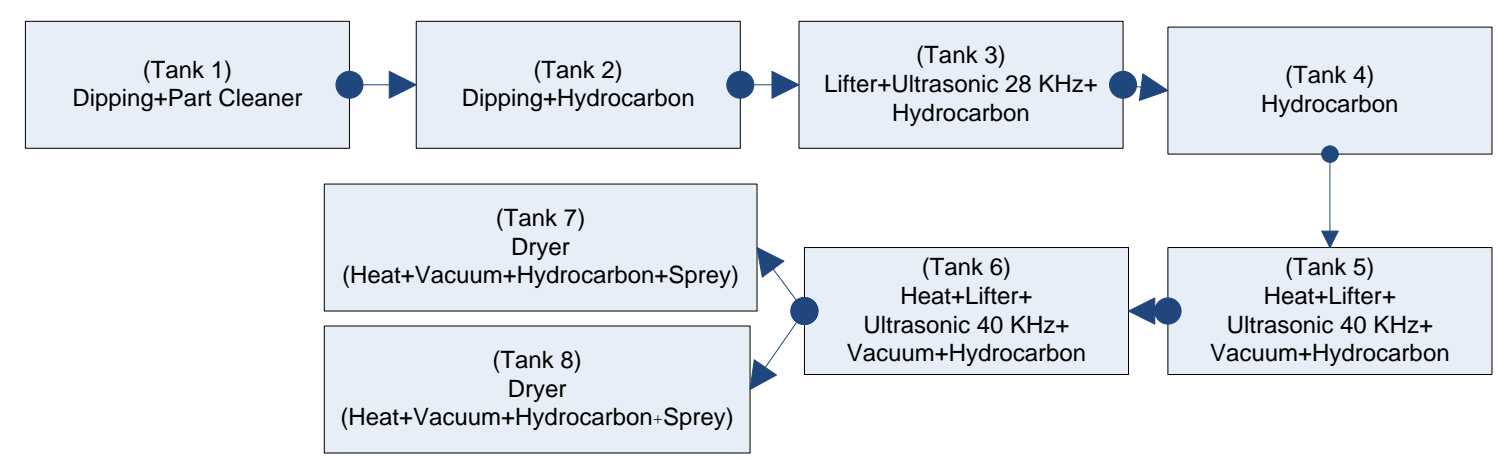

Figure 3. Illustration of flow process of automatic hydrocarbon washing machine.

According to Figure 3, the washing parameters considered for determining the proportion of defectives by oil contamination are the temperature of the vacuum tank, the temperature of dryer tank, and the cycle times of dipping tank no. 1, dipping tank no. 2, the waiting tank, the hydrocarbon tank, the vacuum tank, the dryer tank, and the spray in the dryer tank.

\section{Response Surface Method (RSM)}

The proportion of defectives by oil contamination of hard disk drive parts is important for quality control (Montgomery, 1984). In order to improve the quality of washing, it is necessary to employ theoretical models to develop the function of the washing conditions. The RSM is a collection of mathematical and statistical techniques that are useful for the modeling and analysis of problems. A response of the proportion of defectives is influenced by several parameters. Thus, the objective of this research is to optimize those parameters to reduce the number of defectives by oil contamination.

In most RSM problems, the form of the relationship between the response and the independent variables is unknown. Thus, the first step of the response surface analysis is to establish a suitable approximation for the true functional relationship between the proportion of defectives by oil contamination (y) and the set of independent variables of the washing parameters employed, as shown below:

$$
y=\beta_{0}+\sum_{i=1}^{k} \beta_{i} x_{i}+\sum_{i=1}^{k} \beta_{i i} x_{i}^{2}+\sum_{i} \sum_{j} \beta_{i j} x_{i} x_{j}+\varepsilon
$$

The $\beta$ coefficients used in the above model can be calculated by means of the least squares method. The second-order model is normally used when the response function is unknown or nonlinear (Ross, 1996).

\section{Taguchi Method}

The Taguchi method has been used widely in engineering designs. The main thrust of the Taguchi technique is the use of parameter design, which is an engineering method for the product or the process design that focuses on determining the parameter settings producing the best level of a quality characteristic with minimum variation. The Taguchi method is employed to analyze the washing problems and to find the optimum parameters. The signal-noise $[\mathrm{S} / \mathrm{N}]$ ratio is used as the quality characteristic of choice, 
which is a measurable value, instead of the standard deviation, because as the mean decreases, the standard deviation also decreases, and vice versa. The $\mathrm{S} / \mathrm{N}$ ratio characteristics can be divided into three categories given by equations (2) to (4):

Category 1, nominal is the best characteristic, $\quad \frac{S}{N}=10 \log \frac{\bar{y}}{S_{y}^{2}}$

Category 2, smaller is the best characteristic, $\quad \frac{S}{N}=-10 \log \frac{1}{n}\left(\sum y^{2}\right)$

Category 3 , larger is the best characteristic, $\quad \frac{S}{N}=-10 \log \frac{1}{n}\left(\sum \frac{1}{y^{2}}\right)$

where $\bar{y}$ is the average of observed data, $s_{y}^{2}$ is the variation of $y, n$ is the number of observations, and $y$ is the observed data. For each type of characteristic, it is understood that a smaller $\mathrm{S} / \mathrm{N}$ ratio is the better result.

The orthogonal array for nine factors at three levels is used for the elaboration of the plan of the experiments. The array $\mathrm{L}_{27}$ is selected, which has 27 rows corresponding to the number of tests (26 degrees of freedom). The output to be studied is the proportion of defectives by oil contamination, for which an analysis of variance (ANOVA) was carried out. The steps of the experiments of optimization are presented in Figure 4. The selected levels and factors in the reduction of oil contamination on a part through use of an automatic hydrocarbon washing machine are shown in Table 1.

Table 1. Levels and factors of the experiments.

\begin{tabular}{|c|c|c|c|c|c|}
\hline Level & $\begin{array}{c}\text { (A) } \\
\text { Temperature } \\
\text { of vacuum } \\
\operatorname{tank}\left({ }^{\circ} \mathrm{C}\right)\end{array}$ & $\begin{array}{c}\text { (B) } \\
\text { Temperature } \\
\text { of dryer tank } \\
\left({ }^{\circ} \mathrm{C}\right)\end{array}$ & $\begin{array}{c}\text { (C) } \\
\text { Cycle time } \\
\text { of dipping } \\
\text { tank no. } 1 \\
(\mathrm{sec}) \\
\end{array}$ & $\begin{array}{c}\text { (D) } \\
\text { Cycle time } \\
\text { of dipping } \\
\text { tank no. } 2 \\
(\mathrm{sec}) \\
\end{array}$ & $\begin{array}{c}(\mathrm{E}) \\
\text { Cycle time } \\
\text { of } \\
\text { hydrocarbon } \\
\text { tank (sec) }\end{array}$ \\
\hline 1 & 30 & 90 & 150 & 150 & 150 \\
\hline 2 & 40 & 100 & 180 & 180 & 180 \\
\hline 3 & 50 & 110 & 210 & 210 & 210 \\
\hline Level & $\begin{array}{c}\text { (F) } \\
\text { Cycle time } \\
\text { of waiting } \\
\text { tank (sec) }\end{array}$ & $\begin{array}{c}(\mathrm{G}) \\
\text { Cycle time of } \\
\text { vacuum tank } \\
\left({ }^{\circ} \mathrm{C}\right)\end{array}$ & $\begin{array}{l}(\mathrm{H}) \\
\text { Cycle time } \\
\text { of dryer } \\
\text { tank } \\
(\mathrm{sec})\end{array}$ & \multicolumn{2}{|c|}{$\begin{array}{l}\text { Cycle time of } \\
\text { spray in dryer } \\
\text { tank (sec) }\end{array}$} \\
\hline 1 & 150 & 150 & 600 & \multicolumn{2}{|l|}{180} \\
\hline 2 & 180 & 180 & 660 & \multicolumn{2}{|l|}{240} \\
\hline 3 & 210 & 210 & 720 & \multicolumn{2}{|l|}{300} \\
\hline
\end{tabular}




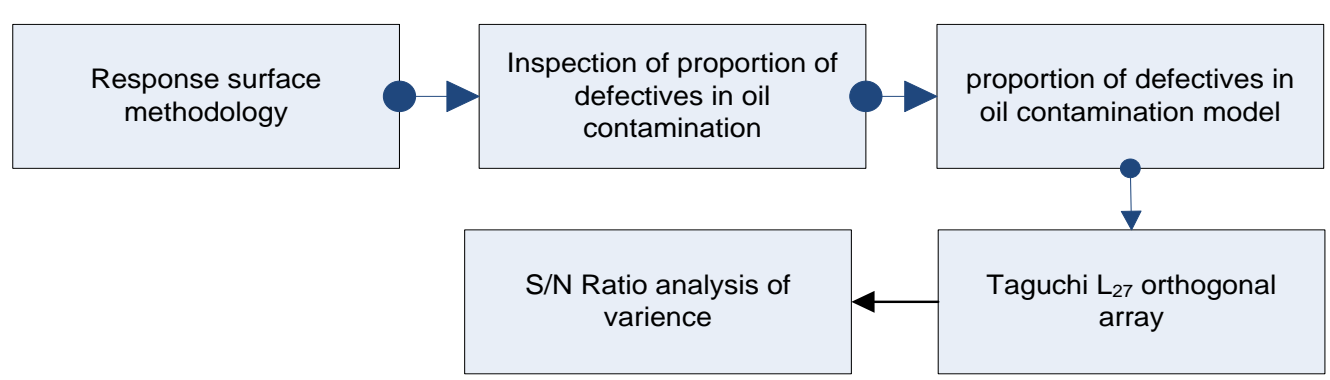

Figure 4. Steps of the optimization process.

\section{RESULTS AND DISCUSSION}

\section{Effect of Parameters on the Proportion of Defectives in Oil Contamination}

The objective of using the $\mathrm{S} / \mathrm{N}$ ratio in the Taguchi method is to obtain a measure of noise factors. The $\mathrm{S} / \mathrm{N}$ ratio for each parameter level is calculated by averaging the $\mathrm{S} / \mathrm{N}$ ratios obtained when the parameter is maintained at that level. Table 2 shows the $\mathrm{S} / \mathrm{N}$ ratios obtained for the different parameter levels. The calculated $\mathrm{S} / \mathrm{N}$ ratio for nine factors on the proportion of defectives of oil contamination for each level is shown in Figure 5. The temperature of the vacuum tank is the dominant parameter on the proportion of defectives of oil contamination. This is followed in order of descending importance by the cycle time of the dryer tank, the cycle time of the spray in the dryer tank, the cycle time of dipping tank no. 2 , the cycle time of dipping tank no. 1 , the cycle time of the waiting tank, the cycle time of the hydrocarbon tank, the cycle time of the vacuum tank, and the temperature of the dryer tank. A lower proportion of defectives of oil contamination is always preferred. The quality characteristic considered in the investigation is "the smaller the better". In the present investigation, when the temperature of the vacuum tank is about $40{ }^{\circ} \mathrm{C}$, the proportion of defectives of oil contamination is a minimum. In contrast to the temperature of this tank, the low temperature has the highest effect. An increase in suitable temperature also decreases the proportion of defectives of oil contamination, as supported by Shetty et al. (2008).

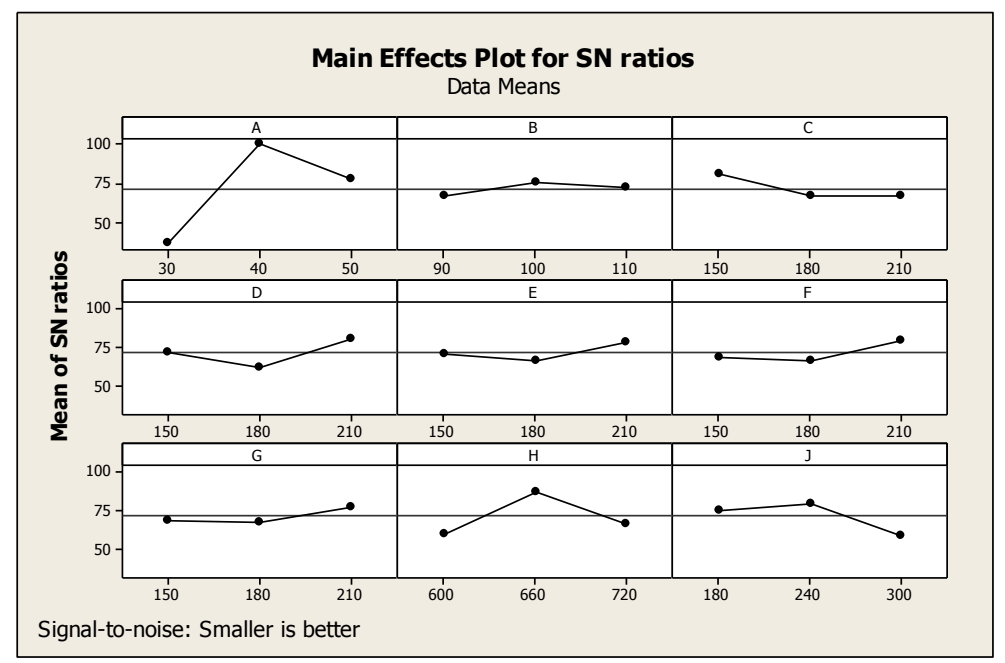

Figure 5. Mean $\mathrm{S} / \mathrm{N}$ graphs for proportion of defectives of oil contamination under different parameters 
Table 2. Response table for $\mathrm{S} / \mathrm{N}$ ratios of the washing parameters: smaller is better (proportion of defectives of oil contamination).

\section{(A)}

Temperature

Level of vacuum $\operatorname{tank}\left({ }^{\circ} \mathrm{C}\right)$
(B)

Temperature of dryer tank

$\left({ }^{\circ} \mathrm{C}\right)$
(C)

(D)

Cycle time of dipping tank no. 1
Cycle time of dipping tank no. 2 $(\mathrm{sec})$
(E)

Cycle time of hydrocarbon tank (sec)

\begin{tabular}{cccccc}
\hline 1 & 36.51 & 67.02 & 80.58 & 72.32 & 70.20 \\
2 & 100.00 & 75.40 & 67.14 & 61.84 & 65.85 \\
3 & 78.18 & 72.27 & 66.97 & 80.53 & 78.64 \\
\hline Delta & 63.49 & 8.38 & 13.61 & 18.69 & 12.78 \\
\hline Rank & 1 & 9 & 5 & 4 & 7 \\
\hline
\end{tabular}

(F)

Level
(G)

Cycle time of waiting tank (sec)
Cycle time of vacuum tank $\left({ }^{\circ} \mathrm{C}\right)$
(H) Cycle time of dryer tank (sec)
(J)

Cycle time of spray in dryer tank (sec)

\begin{tabular}{ccccc}
\hline 1 & 68.20 & 69.14 & 61.01 & 75.52 \\
2 & 66.80 & 67.86 & 86.83 & 79.52 \\
3 & 79.70 & 77.69 & 66.85 & 59.65 \\
\hline Delta & 12.90 & 9.83 & 25.82 & 19.87 \\
\hline Rank & 6 & 8 & 2 & 3 \\
\hline
\end{tabular}

Table 3. ANOVA for S/N Ratio of the proportion of defectives of oil contamination.

\begin{tabular}{ccccccc}
\hline $\begin{array}{c}\text { Source of } \\
\text { Variance }\end{array}$ & DF & SS & MS & F & P & $\begin{array}{c}\text { Contribution } \\
(\%)\end{array}$ \\
\hline A & 2 & 0.046818 & 0.023409 & 15.60 & 0.001 & 30.12 \\
B & 2 & 0.012907 & 0.006453 & 4.30 & 0.027 & 8.30 \\
C & 2 & 0.013730 & 0.006865 & 4.57 & 0.024 & 8.82 \\
D & 2 & 0.009383 & 0.004692 & 3.13 & 0.049 & 6.04 \\
E & 2 & 0.015594 & 0.007797 & 5.20 & 0.018 & 10.04 \\
F & 2 & 0.014264 & 0.007132 & 4.75 & 0.022 & 9.17 \\
G & 2 & 0.011247 & 0.005623 & 3.75 & 0.036 & 7.24 \\
H & 2 & 0.015369 & 0.007684 & 5.12 & 0.019 & 9.88 \\
J & 2 & 0.016156 & 0.008078 & 5.38 & 0.017 & 10.39 \\
\hline Residual Error & 8 & 0.012006 & & & & \\
\hline Total & 26 & 0.167474 & & & & 100 \\
\hline
\end{tabular}

NOTE: $\quad \mathrm{DF}=$ Degrees of freedom, $\mathrm{SS}=$ Sum of Squares, MS = Mean of Squares, $\mathrm{F}=$ Fisher Test, $\mathrm{P}=$ Probability Statistic, 95\% confidence level

The percentage of contribution of the different factors is shown in Table 3 for the proportion of defectives of oil contamination. It can be seen that the temperature of washing in the vacuum tank has the highest contribution of about $30.12 \%$. Thus, the temperature of washing in the vacuum tank is an important factor for consideration when washing the part with the automatic hydrocarbon washing machine. 


\section{Response Surface Analysis}

The second-order response surface representing the proportion of defectives of oil contamination ( $\mathrm{y}$ ) can be expressed as a function of washing parameters, such as the temperature of the vacuum tank (A), the temperature of dryer tank (B), and the cycle times of washing in dipping tank no. 1 (C), washing in dipping tank no. 2 (D), washing in the ultrasonic tank $(\mathrm{E})$, washing in the waiting tank $(\mathrm{F})$, washing in the hydrocarbon tank $(\mathrm{G})$, washing in the dryer tank $(\mathrm{H})$, and of the spray in dryer tank (J). The relationship between the proportion of defectives of oil contamination and the washing parameters can be expressed as:

$$
\begin{aligned}
\mathrm{y}= & \beta_{0}+\beta_{1} \mathrm{~A}+\beta_{2} \mathrm{~B}+\beta_{3} C+\beta_{4} \mathrm{D}+\beta_{5} \mathrm{E}+\beta_{6} \mathrm{~F}+\beta_{7} \mathrm{G}+\beta_{8} \mathrm{H}+\beta_{9} \mathrm{~J}+\beta_{10} \mathrm{~A}^{2}+\beta_{11} \mathrm{~B}^{2} \\
& +\beta_{12} C^{2}+\beta_{13} \mathrm{D}^{2}+\beta_{14} \mathrm{E}^{2}+\beta_{15} \mathrm{~F}^{2}+\beta_{16} \mathrm{G}^{2}+\beta_{17} \mathrm{H}^{2}+\beta_{18} \mathrm{~J}^{2}+\beta_{19} \mathrm{AB}+\beta_{20} A C \\
& +\beta_{21} \mathrm{AD}+\beta_{22} \mathrm{AE}+\beta_{23} \mathrm{AF}+\beta_{24} \mathrm{AG}+\beta_{25} \mathrm{AH}+\beta_{26} \mathrm{AJ}+\beta_{27} B C+\beta_{28} B D+\beta_{29} B E \\
& +\beta_{30} \mathrm{BF}+\beta_{31} \mathrm{BG}+\beta_{32} \mathrm{BH}+\beta_{33} \mathrm{BJ}+\beta_{34} C D+\beta_{35} C E+\beta_{36} C F+\beta_{37} C G+\beta_{38} C H \\
& +\beta_{39} C J+\beta_{40} \mathrm{DE}+\beta_{41} \mathrm{DF}+\beta_{42} \mathrm{DG}+\beta_{43} \mathrm{DH}+\beta_{44} \mathrm{DJ}+\beta_{45} \mathrm{EF}+\beta_{46} \mathrm{EG}+\beta_{47} \mathrm{EH} \\
& +\beta_{48} \mathrm{EJ}+\beta_{49} \mathrm{FG}+\beta_{50} \mathrm{FH}+\beta_{51} \mathrm{FJ}+\beta_{52} \mathrm{GH}+\beta_{53} \mathrm{GJ}+\beta_{54} \mathrm{HJ}
\end{aligned}
$$

From the observed data for the proportion of defectives of oil contamination, the response function with $\mathrm{R}^{2}=99.85$ has been obtained and determined in uncoded units as:

$$
\begin{aligned}
\mathrm{y}= & 5.52882-0.04949 \mathrm{~A}+0.001032 \mathrm{~B}+0.0058 \mathrm{C}+0.00392 \mathrm{D}+0.01585 \mathrm{E}+0.01974 \mathrm{~F} \\
& +0.01201 \mathrm{G}-0.02953 \mathrm{H}-0.00416 \mathrm{~J}+0.0005 \mathrm{~A}^{2}-0.00004 \mathrm{~B}^{2}-0.00001 \mathrm{C}^{2}-0.00001 \mathrm{D}^{2} \\
& -0.00005 \mathrm{E}^{2}-0.00005 \mathrm{~F}^{2}-0.00004 \mathrm{G}^{2}+0.00002 \mathrm{H}^{2}+0.00002 \mathrm{~J}^{2}-0.00004 \mathrm{AH} \\
& -0.00001 \mathrm{AJ}+0.00001 \mathrm{BE}-0.00002 \mathrm{BF}+0.00003 \mathrm{BG}-0.00001 \mathrm{BH}+0.00001 \mathrm{BJ}
\end{aligned}
$$

Table 4. ANOVA table for response surface of the proportion of defectives of oil contamination.

\begin{tabular}{cccccc}
\hline $\begin{array}{c}\text { Source of } \\
\text { Variance }\end{array}$ & DF & SS & MS & F & P \\
\hline Regression & 25 & 0.16747 & 0.00670 & 715.99 & 0.03 \\
Residual Error & 1 & 0.00001 & 0.00001 & & \\
\hline Total & 26 & & & & \\
\hline
\end{tabular}

NOTE: $\mathrm{DF}=$ Degrees of freedom, $\mathrm{SS}=$ Sum of Squares, $\mathrm{MS}=$ Mean of Squares,

$\mathrm{F}=$ Fisher Test, $\mathrm{P}=$ Probability Statistic

The result of the ANOVA for the response function of the proportion of defectives of oil contamination is presented in Table 4. This analysis is carried out at the high significance level of 0.05 ; hence, the second-order response function developed is quite reliable and promising. From equation (6), examples of the contour plots of the proportion of defectives of oil contamination at the cycle time of the dryer tank and the cycle time of the spray in dryer tank are shown in Figure 6. These contour plots can help predict the proportion of defectives of oil contamination at any zone of the experimental domain. It is clear that the proportion of defectives of oil contamination decreases with a 
suitable increase in temperature and cycle time.

The response optimization of the washing parameters for the proportion of defectives of oil contamination is shown in Figure 7. These are vacuum tank temperature of $44.9495{ }^{\circ} \mathrm{C}$, dryer tank temperature of $90{ }^{\circ} \mathrm{C}$, cycle time of dipping tank no. 1 of $150 \mathrm{sec}$, cycle time of dipping tank no. 2 of $150 \mathrm{sec}$, cycle time of ultrasonic tank of $210 \mathrm{sec}$, cycle time of waiting tank of $210 \mathrm{sec}$, cycle time of vacuum tank of 210 sec, cycle time of dryer tank of $658.182 \mathrm{sec}$, and the cycle time of the spray in the dryer tank of 247.879 sec.

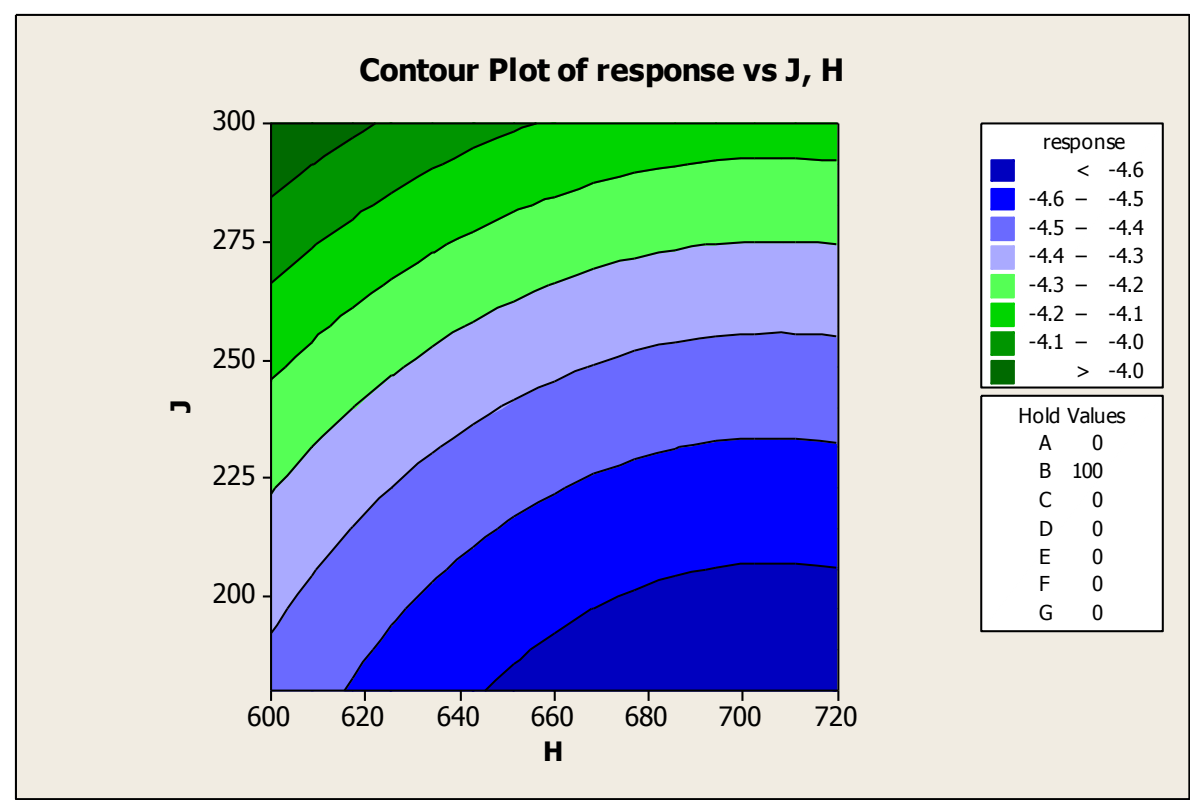

(a)

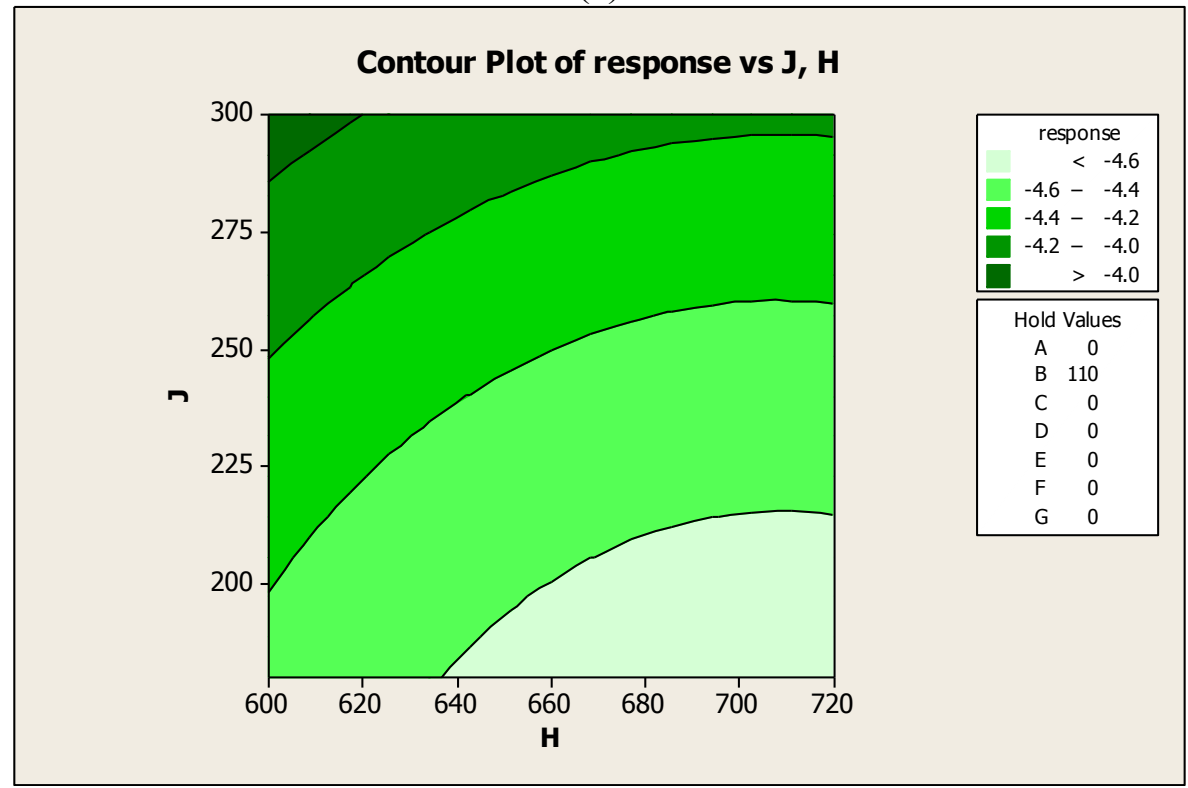

(b)

Figure 6. Contour plot of proportion of defectives of oil contamination at the cycle time of dryer tank and the cycle time of spray in dryer tank for different temperatures: a) $100{ }^{\circ} \mathrm{C}$, and b) $110^{\circ} \mathrm{C}$. 


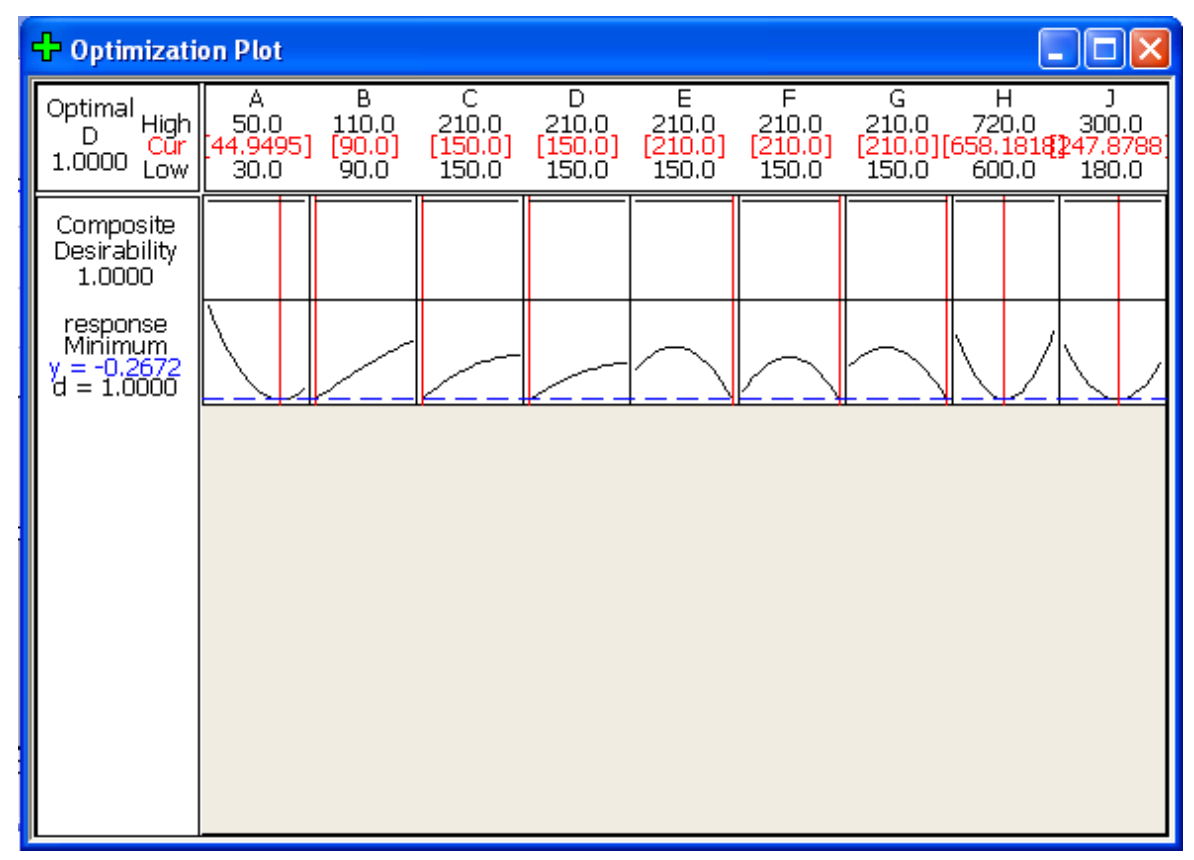

Figure 7. Illustration of response optimization plots of washing parameters for minimum proportion of defectives of oil contamination with the automatic hydrocarbon washing machine.

\section{Confirmation Experiments}

The confirmation experiments are conducted with the optimal process parameters, as shown in Figure 7. The experimentally obtained results from the optimization process and the measured values are close and within the target $3 \%$ proportion of defectives of oil contamination at the high significance level of 0.05 , as shown in Table 5. This indicates that the developed model can be used effectively to predict the proportion of defectives of oil contamination in washing when using the automatic hydrocarbon washing machine.

Table 5. Percentage of oil contamination obtained from the confirmation experiments

\begin{tabular}{cc}
\hline Lot & \% oil contamination \\
\hline 1 & 0 \\
2 & 0 \\
3 & 0 \\
4 & 0.1015 \\
5 & 0.1013 \\
6 & 0.3040 \\
7 & 0 \\
8 & 0.6667 \\
9 & 0 \\
10 & 0.2584 \\
\hline
\end{tabular}




\section{CONCLUSION}

The effects of the different washing conditions in reducing oil contamination on hard disk drive parts by using an automatic hydrocarbon washing machine have been evaluated with the Taguchi method and response surface analysis. The optimal washing conditions for minimizing the proportion of defectives of oil contamination have been determined. It is found that the temperature of the vacuum tank is the dominant parameter affecting the proportion of defectives of oil contamination. This is followed in descending order of importance by the cycle time of the dryer tank, the cycle time of the spray in the dryer tank, the cycle time of dipping tank no. 2, the cycle time of dipping tank no.1, the cycle time of the waiting tank, the cycle time of the hydrocarbon tank, and the cycle time of vacuum tank. The temperature of the dryer tank has much lower effect compared with other parameters. In order to obtain a low percentage of oil contamination on hard disk drive parts, suitably high values of the temperature of the vacuum tank and cycle times of the dryer tank and of the spray in the dryer tank are preferred. The response surface analysis provides a large amount of information from a small numbers of experiments. A second-order response surface model for the proportion of defectives of oil contamination has been developed from the observed data. The model can be used effectively to predict the proportion of defectives of oil contamination when using the automatic hydrocarbon washing machine with $95 \%$ confidence level. The use of the developed model can obtain remarkable savings in production time and production cost.

\section{ACKNOWLEDGEMENTS}

This research is supported by Integrated Precision Engineering Co. Ltd., (Thailand) from 2008 to 2009.

\section{REFERENCES}

Angsumalin, S., Somkiat, T., \& Napassavong, R. (2008). Improvement of washing process for machining part due to oil contamination. Journal of IE network Conference, Thailand, pp. 465-469.

Kadirgama, K., Noor, M. M., Rahman, M. M., Bakar, R. A., \& Abou-El-Hossein, K. A. (2009a). Fourth order torque prediction model in end milling. Journal of Applied Sciences, 9(13), 2431-2437.

Kadirgama, K., Noor, M. M., Rahman, M. M., Rejab, M. R. M., Haron, C. H. C., \& Abou-El-Hossein, K. A. (2009b). Surface roughness prediction model of 6061T6 aluminium alloy machining using statistical method. European Journal of Scientific Research, 25(2), 250-256.

Kwak, J. S. (2005). Application of Taguchi and response surface methodologies for geometric error in surface grinding process. International Journal of Machine Tools and Manufacturing, 45, 327-334.

Montgomery, D. C. (1984). Design and analysis of experiments. New York: John Wiley and Sons.

Reddy, B. S., Kumar, J. S., Reddy, K., Vijaya, K., \& Kumari, A. A. (2009). Application of Taguchi and response surface methodology for biodiesel production from alkali catalysed transesterification of waste cooking oil. International Journal of Applied Engineering Research, 4(7), 1169-1184. 
Ross, P. J. (1996). Taguchi Techniques for quality engineering: loss function, orthogonal experiments, parameter and tolerance design. New York: McGraw-Hill.

Sahin, Y., \& Motorcu, A. R. (2005). Surface roughness model for machining mild steel with coated carbide tool. Journal of Materials and Design, 26, 321-326.

Shetty, R., Pai, R., Rao, S. S., \& Kamath, V. (2008). Machinability study on discontinuously reinforced aluminium composites (DRACs) using response surface methodology and Taguchi's design of experiments under dry cutting condition. Maejo International Journal of Science and Technology, 2(1), 227239.

Yang, W. H., \& Tarng, Y. S. (1998). Design optimization of cutting parameters for turning operations based on the Taguchi method. Journal of Material Processing Technology, 84, 122-129. 